
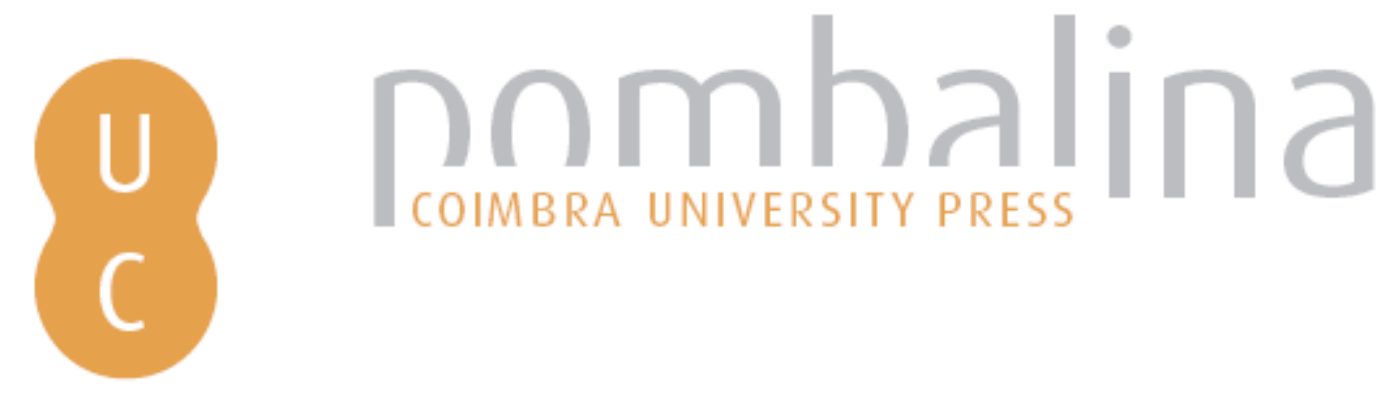

\title{
A transformação do espaço funerário no ocidente entre os séculos iv e vi. Ambiguidades e loci sepulturae em espaços rurais do sul da Lusitânia: o caso dos templos
}

Autor(es): $\quad$ Bernardes, João Pedro

Publicado por: Imprensa da Universidade de Coimbra

URL persistente:

URI:http://hdl.handle.net/10316.2/42129

DOI:

DOI:https://doi.org/10.14195/978-989-26-1353-6_15

Accessed : $\quad$ 26-Apr-2023 05:47:56

A navegação consulta e descarregamento dos títulos inseridos nas Bibliotecas Digitais UC Digitalis, UC Pombalina e UC Impactum, pressupõem a aceitação plena e sem reservas dos Termos e Condições de Uso destas Bibliotecas Digitais, disponíveis em https://digitalis.uc.pt/pt-pt/termos.

Conforme exposto nos referidos Termos e Condições de Uso, o descarregamento de títulos de acesso restrito requer uma licença válida de autorização devendo o utilizador aceder ao(s) documento(s) a partir de um endereço de IP da instituição detentora da supramencionada licença.

Ao utilizador é apenas permitido o descarregamento para uso pessoal, pelo que o emprego do(s) título(s) descarregado(s) para outro fim, designadamente comercial, carece de autorização do respetivo autor ou editor da obra.

Na medida em que todas as obras da UC Digitalis se encontram protegidas pelo Código do Direito de Autor e Direitos Conexos e demais legislação aplicável, toda a cópia, parcial ou total, deste documento, nos casos em que é legalmente admitida, deverá conter ou fazer-se acompanhar por este aviso.

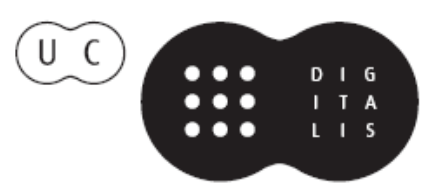




\section{Arqueologia \\ da transição:}

entre o mundo romano

e a Idade Média

Cláudia Teixeira, André Carneiro (coords.)

IMPRENSA DA UNIVERSIDADE DE COIMBRA

ANNABLUME 


\title{
A transformação do espaço FUnerário no ocidente Entre os SÉCULOS IV E VI. AMBiguidAdES E LOCI SEPULTURAE EM ESPAÇOS RURAIS DO SUL DA LUSITÂNIA: O CASO DOS TEMPLOS (Funerary areas transformations in the in the west between IVth and VIth centuries. Ambiguities and loci sepulturae in south Lusitania rural spaces: the temples case)
}

\author{
João Pedro Bernardes (jbernar@ualg.pt) \\ Universidade do Algarve
}

Resumo - Após os cuidados tidos com os locus sepulturae, comprovados por dados epigráficos e pela literatura clássica de época imperial, uma profunda alteração na organização de muitas necrópoles e espaços de enterramento surge a partir do século quarto. Esta mudança resulta da gradual decadência dos modelos de gestão imperiais, mas também da afirmação de uma nova perspetiva de entendimento do universo mental e religioso. Do ponto de vista arqueológico, agora existem novas realidades na deposição sepulcral e na topografia funerária, quer em áreas urbanas, quer rurais, que são sintomas de novas conceções religiosas no mundo como a vida além-túmulo é concebida. Contudo, também evidenciam mudanças nos poderes e formas de gestão social, e mesmo na desregulação da ars moriendi, típica de um momento de grandes conflitos religiosos e mentais. A transição observada em certos espaços sepulcrais na Hispania, o comportamento de práticas funerárias pagãs na sua relação com os loci sepulturae cristãos ou a discussão sobre os seus conteúdos e significados em época de grandes ambiguidades e temores, são os principais temas tratados no presente estudo. Argumenta-se que, ao invés de uma cristianização de templos rurais no século v ou vi e sua conversão para igrejas cristãs, o que ocorre é a apropriação destes loci sacer para a deposição funerária cristã, num tempo em que os teólogos e a hierarquia da Igreja desvalorizavam e não punham constrangimentos aos rituais de deposição funerária dos seguidores de Cristo.

Palavras-chave - Antiguidade Tardia, templos rurais, áreas sepulcrais, Cristianização.

Aвstract - After the care concerning the locus sepulturae, testified by epigraphy or imperial classic literature, there is, from the fourth century, a profound change in the organization and arrangement of many necropolis and burial spaces. This change resulted from the gradual decay of organizational structures, but also the emergence and affirmation of a new way of seeing the world within the framework of a new mental and religious universe. From the archaeological viewpoint, there are new and different realities with the topography and with the sepulchral deposition, both in urban and in rural areas, and that are symptom of religious conceptions from after-life in transition; but they are also evidence of mutation of powers and even a certain vagueness and deregulation of ars moriendi, typical of a period of great religious and mental conflicts. The observation of the transition of some sepulchral spaces in rural areas of Hispania, the behavior of pagan religious spaces in its relation to the Christian loci sepulturae or the discussion of its potential contents and meanings in a world of many ambiguities 
and anxieties, are the main topics of this text. It is argued that, unlike a Christianization of rural temples of the Roman villae in the 5th and 6th centuries, and their conversion into Christian churches, what actually happens is an appropriation those loci sacer for the deposition of the dead Christians, at a time when the theologians and the Church hierarchy devalued and have not set requirements for sepulchral areas and burial rituals of the followers of Christ.

KeYwords - Late antiquity, rural temples, burial areas, Christianization.

\section{A organização dos espaços FUnerários ENTRE os Romanos}

A separação entre o espaço dos vivos e dos mortos na época romana era bem regulamentada e estritamente observada, quer em meio urbano, quer em meio rural. É assim que o jurisconsulto Paulo afirma que "nenhum cadáver deve ser colocado na cidade, para que os sacra da cidade não sejam manchados”, prescrições estas que estando já presentes na Lei das XII Tábuas, em 452 a.C., e em vários códices, acabam por ser revogadas pelo imperador Leão I (Flavius Valerius Leo) na segunda metade do século v. O espaço funebris, que se dispunha preferentemente ao longo das vias, mais por uma questão de proximidade com os vivos, entre os quais se procurava preservar a memória dos defuntos, do que por razões de acessibilidade, obedecia igualmente a regras bem definidas que visavam organizar todo o espaço de acordo com uma planta racional. A necrópole era assim frequentemente delimitada e protegida por um recinto murado e dividido em talhões que se adquiriam, em tamanho maior ou menor, ocupando áreas mais ou menos expostas, de acordo com as posses e o estatuto do adquirente.

Essas parcelas poderiam ser bem mais vastas do que o necessário para a deposição do corpo ou túmulo, pelo que havia uma preocupação constante de impedir a alienação da terra adquirida. Era pois natural que em muitos monumentos se apresentassem as medidas dos talhos de terra pertencentes à respetiva sepultura, como é o conhecido caso de Trimalquião, herói do livro Satiricon (LXXI) de Petrónio:

Pois bem meu caro amigo, encarregas-te de elevar o meu monumento como eu te pedi? (...) E que este monumento tenha cem pés (cerca de 30 metros) de frente e duzentos de profundidade. Com efeito quero que ele tenha todas as espécies de frutos à volta das minhas cinzas, e vinhas em abundância. Nada é mais absurdo que ter em vida casas bem guarnecidas, e de não cuidar aquelas onde devemos permanecer por muito mais tempo. É por isso que, acima de tudo, quero que se acrescente: 'este monumento não faz parte da herança'(...) Recomendarei um dos meus libertos para guardar o meu túmulo.

\footnotetext{
${ }^{1}$ Ariès 1988: 41-42.
} 
O texto de Petrónio revela a preocupação com o arranjo (inclusive paisagístico) da última morada, mas também com a perpetuação deste lugar de memória a fim de que seja evitada essa segunda morte, ou morte definitiva, que é o esquecimento.

A observância com a organização do espaço funerário é também motivo de preocupação por parte dos municípios, como demonstram os capítulos 73 e 74 da lex Ursonensis que tratam das disposições funerárias ${ }^{2}$. É claro que, na prática, a sua aplicação era subvertida com frequência, em virtude da expansão das áreas urbanas, bem patente em Córdova ou Roma ${ }^{3}$, pela reutilização de materiais, pela sobreposição de sepulturas, ou ainda por roubos e usurpações que aconteciam um pouco por todo o lado.

Estas práticas de usurpação de loci sepulturae mais antigos, para ali se fazerem novos enterramentos, constituíam uma autêntica violatio sepulchris que estava prevista e era severamente condenada pela legislação de muitos municípios que instituíam multas funerárias para os violadores, como ocorre nas referidas leis de Urso, mas também nas de Irni ${ }^{4}$. Durante o Baixo-império e à medida que se avolumam os indícios que anunciam uma paulatina transformação, retração e decadência urbana estes, como muitos outros, preceitos das comunidades urbanas tendem cada vez mais a não serem seguidos. Em vários espaços urbanos, de que o de Ossonoba (atual cidade de Faro) é um bom exemplo, as necrópoles tornam-se cada vez mais desorganizadas e com uma reutilização crescente de materiais e até de estruturas de enterramento. $\mathrm{O}$ mesmo fenómeno observa-se também em meio rural e, à medida que se torna mais evidente o desmantelamento das estruturas político-administrativas e a diluição dos padrões de vida socioeconómica típicos do classicismo romano, surgem novos espaços de enterramento pouco organizados e distribuídos um pouco por todo o lado.

\section{As transformações no SÉculo v: Tempos de Conflitualidade INTERNA, ENTRE CONCEÇÕES PAGÃS E CRISTÃS}

As alterações verificadas a partir do século IV na organização da sociedade e nas mentalidades, com a progressão do cristianismo e das novas conceções do além que a adoção à nova religião traz, terão sido as principais causas - mas não as únicas - que explicam a mudança na forma como se organizam e distribuem na topografia urbana os espaços funerários. É certo que, sobretudo nas grandes

\footnotetext{
${ }^{2}$ López Melero 1997; para além deste artigo referente às disposições funerárias da legislação de Urso (actual cidade de Osuna), o estudo monográfico deste vol. 15 da Stvdia Historica analisa em vários artigos as restantes disposições constantes daquela lei.

${ }^{3}$ Vaquerizo 2001: 139-140.

${ }^{4}$ Vaquerizo 2001: 52; a legislação municipal de Irni (E1 Saucejo, Sevilha), pode ser vista em D'ors A., Lex Irnitana (Texto bilingüe), Santiago de Compostela, 1988.
} 
necrópoles romanas, os enterramentos continuam a fazer-se nos mesmos lugares; mas, agora, são mais caóticos, sobrepondo-se frequentemente a antigas sepulturas, como se observa nos campos mortuários emeritenses, ou não obedecendo a qualquer organização, como se constata de forma muito clara no largo 25 de Abril da grande necrópole de Ossonoba ${ }^{5}$.

Para além da continuidade de enterramentos em necrópoles pagãs e da sua crescente desorganização, as alterações que se verificam na paisagem funerária do Ocidente Peninsular, a partir do século IV ou inícios do v, pautam-se também pela deslocalização dos campos mortuários para junto das áreas residenciais e ainda por uma certa dispersão das sepulturas, fenómeno particularmente bem evidente no meio rural, onde as antigas termas e determinadas partes mais nobres das villae já desativadas recebem enterramentos. Este fenómeno, mais ou menos disperso, de utilizar como áreas funerárias antigos espaços residenciais ou públicos, visa demarcar as sepulturas cristãs dos antigos loci sepulturae pagãos, anunciando já a prática medieval de aproximação e até de promiscuidade dessas sepulturas com os lugares dos vivos. Esta procura de novos espaços funerários é bem clara em Silveirona II, local de enterramento cristão a 300 metros da necrópole pagã de Silveirona I, em Torre de Palma, e em muitos outros sítios do sul da Lusitânia de que poderíamos referir a título de exemplo, Quinta de Marim, Álamo (Alcoutim), Cerro da Vila ou Milreu 6 . A tendência para aproximar o espaço dos mortos do dos vivos, independentemente da existência ou não de um local de culto, é também comum nos meios urbanos, vendo-se testemunhada em Córdoba, onde a retração da área urbana é ocupada por pequenos recintos funerários ${ }^{7}$, ou em Mértola, onde a necrópole romana da Achada de S. Sebastião é abandonada a partir de meados do séc. V para se passar a utilizar a do Rossio do Carmo que receberá uma basílica ${ }^{8}$.

A motivação para a escolha do novo local mortuário parece obedecer a um sentimento algo paradoxal. Se o seguidor da nova religião pretende fazer-se enterrar numa área funebris não pagã, procura, simultaneamente, manter alguma proximidade com o locus sacer ou o locus religiosus que o espaço da morte ou de

\footnotetext{
${ }^{5}$ Para a realidade emeritense, entre os muitos títulos que têm vindo a lume na última década, veja-se Nogales Bassarrate e Marquez Perez 2002; Alba Calzado 2004; para o caso da necrópole Ossonobensis que terá sido ocupada até ao século vi, veja-se Teichner et al. 2007.

${ }^{6}$ Veja-se Cunha, 2008 para Silveirona; para Torre de Palma, Maloney e Hale 1996 e, especificamente para os espaços funerários, a recente tese de doutoramento de M. Wolfram 2011 (particularmente as páginas 251-252). Para os sítios algarvios de Quinta de Marim veja-se Graen 2007, para a villa do Álamo, Santos 1972: 367-372, e para Milreu e Cerro da Vila Teichner 2008: 95-107; 250-256; 280-285. Na villa do Álamo, da qual se conhece apenas os levantamentos efectuados por Estácio da Veiga, regista-se uma necrópole situada a cerca de 150 metros a norte da villa, e um outro conjunto de sepulturas que perfuraram os pavimentos de alguns compartimentos da villa.

${ }^{7}$ Sánchez Ramos 2007 e 2010.

${ }^{8}$ Macias 2005: 225.
} 
culto pagão sempre representava, ou ainda com um referente de prestígio que facilite o estatuto de memoria que se quer para a sepultura. Numa época de profundas incertezas e angústias, os recém aderentes à nova religião deparavam-se com a constante ansiedade de saber onde se enterrarem uma vez que a própria Igreja ainda não definira quaisquer regras ou rituais de enterramento; problema ainda maior, obviamente, em áreas rurais distantes dos núcleos urbanos, onde a escassa densidade populacional e a maior dificuldade de penetração do cristianismo levava a que não existissem locais de culto ou de referência cristãos. $\mathrm{Na}$ hora da morte os rustici, mais do que os restantes cristãos, encontram-se perante um angustiante dilema: ou enterravam os seus mortos num espaço próprio de ligação ao além por ser habitado pelos Manes e, por isso mesmo, locus sacer mas também pagão, ou se afastavam desse lugar inumando em sítios sem qualquer estatuto sagrado ou de ligação ao além. Várias práticas consideradas heréticas e alguns documentos conciliares refletem essas muitas indefinições e hesitações geradoras de ansiedade. Com efeito, neste período caracterizado pela dualidade religiosa paganismo-cristianismo é natural uma certa confusão, não apenas à hora da morte, demonstrada em várias pautas de comportamento social e que transparece desde cedo na legislação eclesiástica, mas também a que decorre dos primeiros cânones do concílio de Elvira, onde se dá particular atenção aos cristãos que, sendo batizados, continuam a praticar rituais e obrigações pagãs ${ }^{9}$. Tendo estas mesmas preocupações com a unidade religiosa e a idolatria, o II Concílio de Braga dedica alguns dos seus cânones a combater as traditiones gentilium relacionadas com os enterramentos, como proibir aos clérigos a celebração de missas sobre as sepulturas (Cânone LXVIII), ou aos cristãos de levar alimentos e realizar sacrifícios juntos às sepulturas em honra dos mortos (Cânone LXIX $)^{10}$.

Sendo omissa relativamente aos lugares indicados para enterramento dos fiéis, é natural que a Igreja não condenasse explicita e categoricamente os enterramentos cristãos em necrópoles pagãs ${ }^{11}$. Quando essas condenações existem elas referem-se mais à participação nos rituais fúnebres dos pagãos e não tanto ao lugar da sepultura. É o caso de Cipriano de Cartago em meados do século III, que, numa carta às comunidades hispânicas, critica especificamente o bispo de Mérida, Marcial, por ter recorrido a rituais pagãos e ao espaço sepulcral de um colégio funerário, com tudo o que isso implicava, para enterrar o seu filho ${ }^{12} . \mathrm{Na}$ verdade, e sobretudo quando consideramos o espaço rural nos séculos iv ou v da

\footnotetext{
${ }^{9}$ Vives 1963: 1-2; Arce 2006: 120.

${ }^{10}$ Vives 1963: 102.

${ }^{11} \mathrm{O}$ primeiro cemitério cristão comunitário da Igreja de Roma corresponde às famosas catacumbas de Calisto na via Ápia, no ano de 197. Entende-se por cemitério cristão a instituição de um lugar de sepultura destinado ao conjunto dos fiéis, reservado só para eles, mais ou menos delimitado e sob o controlo da Igreja (Rébillard 1999:1028).

${ }^{12}$ Cipriano, Ep. 67; Rébillard 1999: 1029-1031; Rébillard 2003: 28
} 
Hispânia, os teólogos cristãos não estavam em condições de interditar o acesso às necrópoles pagãs, uma vez que, relegando os atos fúnebres para a esfera familiar ou corporativa através dos collegia funebris, não ofereciam qualquer espaço alternativo para o efeito. Nas suas Confissões (Liv. IX, 11.27), Santo Agostinho ao descrever a morte de Mónica, sua mãe, conta que a convalescente terá dito a si e ao seu irmão: "Sepultai este corpo em qualquer lugar: que em nada vos perturbe a preocupação com isso; somente vos peço isto: que vos lembreis de mim diante do altar do Senhor, onde quer que estiverdes" ${ }^{\prime 13}$. Compreende-se, pois, que Santo Agostinho num dos seus sermões diga que mais importante que o local onde se deposita o corpo é o que se fez com ele em vida, ou seja, "os méritos dos mortos não são determinados pelos lugares onde se encontram os seus corpos, mas pelas disposições em que se encontram as suas almas" ${ }^{14}$. No De cura pro mortuis gerenda, o mesmo teólogo volta a desvalorizar, numa carta a Paulino, bispo de Nola, o lugar de sepultura, não vendo mais uma vez qualquer necessidade ou utilidade aos rituais de enterramento ${ }^{15}$. Esta carta ao bispo daquela cidade da Campânia, que é a resposta a uma outra onde este pede a opinião do consagrado teólogo sobre os benefícios de uma sepultura $a d$ sanctus, não deixa de ser ilustrativa da indefinição que reinava sobre o tema mesmo entre a hierarquia da Igreja.

Independentemente do local de enterramento, todo o crente, por uma questão de caridade e de misericordiosa obrigação cristã, tinha o dever de enterrar quem quer que fosse que necessitasse de sepultura ${ }^{16}$. Mas é um dever ético, pessoal, que decorre do dever de piedade que qualquer cristão deve praticar, e não de uma obrigatoriedade comunitária ou pública. A igreja, que elabora ritos cristãos religiosos, como a Comunhão à hora da morte, não encara, durante os séculos IV a VI, o culto dos mortos como algo público ou comunitário que lhe caiba organizar, razão pela qual não vê necessidade ou obrigação de criar espaços específicos de enterramento para os cristãos. Esta ausência de preocupações com o lugar da sepultura por parte das autoridades religiosas, mais centradas em combater as ameaças heréticas, acabarão por promover os enterramentos ad sanctos, sobretudo a partir do século vi, mas, até à constituição desses lugares de

${ }^{13}$ Santo Agostinho, Confissões, Lisboa, 2000, p. 419 (tradução e notas de Arnaldo do Espírito Santo, João Beato e Maria Cristina Pimentel).

${ }_{14}$ "Nam mortuorum merita adtenduntur, non in locus corporum, sed in adfectibus animarum" (apud Rébillard 1999: 1041).

${ }^{15} \mathrm{O}$ De cura pro mortuis gerenda (O cuidado devido aos mortos), escrito em 421, é o tratado mais importante desta época sobre as questões funerárias. No seu capítulo I diz-se especificamente que "é através do modo de vida que cada um levou durante a existência corpórea, que se determina a utilidade ou inutilidade desses auxílios que lhes são piedosamente dedicados após a morte" (a este propósito pode ver-se ainda Rébillard 1999: 1039).

${ }^{16}$ A atenção e importância atribuída pelos cristãos ao "serviço dos mortos", nomeadamente provendo-lhes uma sepultura, será, segundo o imperador Juliano (Ep. 84, 429d-430a), uma das razões do sucesso do cristianismo. 
santidade e de referência para os enterramentos cristãos, subsistem múltiplas ambiguidades e incertezas.

A separação entre religião cristã e culto dos mortos é, pois, uma realidade nos primeiros tempos cristãos, encarando-se aquele como algo da esfera privada e familiar, o que em grande parte explica que muitas das concentrações de algumas sepulturas dispersas pelas áreas das villae ou das cidades, nos séculos V e VI, correspondam a pequenas necrópoles de cariz familiar. Esta dispersão vai desaparecer relativamente cedo nos núcleos urbanos para dar lugar à concentração dos enterramentos junto aos locais de culto. Todavia, nos meios rurais essa definição do locus funebris, como se viu, tem mais dificuldade em se fazer. Só a partir do século viı, por via de uma implantação crescente nos campos da fé cristã, em grande parte suportada pelo fenómeno monástico, esta realidade tende a mudar. Na Regula monachorum (PL, 83, 893-894) de Isidoro de Sevilha, por exemplo, já se diz que "é necessário enterrar os corpos dos irmãos num único lugar, de forma que aqueles que vivam em conjunto na unidade da caridade, estejam reunidos na morte num único lugar". Mas a primeira lei proibindo enterramentos de cristãos e pagãos no mesmo espaço data apenas de $782^{17}$.

Nesta primeira fase que percorre o Ocidente peninsular no século v, os cristãos tiveram que ser inventivos na escolha do lugar para a morada eterna e, se alguns indivíduos continuam a optar pelos loci funebris pagãos, outros escolhem novos lugares onde se sintam mais confortáveis no âmbito das suas convicções religiosas do além. E, aqui, as escolhas são múltiplas e variadas: uns optarão por se fazerem enterrar em locais monumentais de prestígio, com dignitas e uma forte carga identitária, como as ricas áreas de receção das villae; outros, em locais que, de alguma forma, suscitem alegoricamente os ritos de iniciação ou sejam propiciatórios da lavagem dos pecados que a passagem para um além bem-aventurado sempre exige; outros ainda escolhem sítios com uma mística sagrada como os que ficam próximo dos templos ou de necrópoles pagãs. É assim recorrente que os primeiros enterramentos cristãos ocorram nas áreas residenciais das villae ou nas suas termas, edifícios ligados à água e à lavagem do corpo e que simbolicamente serão mais propícios a locais de passagem e à purificação da alma. Sobre alguns destes enterramentos em termas surgirão pouco depois algumas basílicas, como nas villae do Monte da Cegonha, de El Saucedo e, provavelmente, na de S. Romão, Alvito ${ }^{18}$. Talvez esta mesma atração por locais de alguma forma conotados com a água e, portanto, com a lavagem, a purificação, ou o batismo, ajude a explicar a localização de alguns campos mortuários sobre cetariae de complexos

\footnotetext{
${ }^{17}$ Rébillard 2003:42.

${ }^{18}$ Sobre o aproveitamento das termas como locais funerários veja-se Garcia Entero 2005-2006. Para o caso específico de S. Romão, Wolfram 2011: 184.
} 
piscícolas como se verifica em Fuengirola, ${ }^{19}$ Tróia,${ }^{20}$ ou Loulé Velho ${ }^{21}$ que, nos últimos casos, também receberam basílicas.

É esta mesma mentalidade que busca locais conotados com o sagrado e a memoria que está subjacente em muitas outras villae ou núcleos de povoamento, como o Cerro da Vila ${ }^{22}$, onde a partir do século v surgem novos campos funerários demarcados mas adjacentes aos anteriores (Fig. 1). Naquele aglomerado secundário o novo recinto sepulcral, no seu movimento de aproximação à área dos vivos, vai situar-se junto ao mausoléu templiforme que ficava a cerca de 100 metros da necrópole romana; também em grandes villae do sul da Lusitânia, como Milreu ou S. Cucufate, as novas necrópoles fixam-se nas áreas do temenos dos respectivos templos ou suas imediatas proximidades. Nestes últimos casos os templos pagãos exercem uma clara atração sobre os enterramentos tardo-antigos ou paleocristãos, o que tem sido interpretado como indicador da cristianização desses mesmos templos ${ }^{23}$.

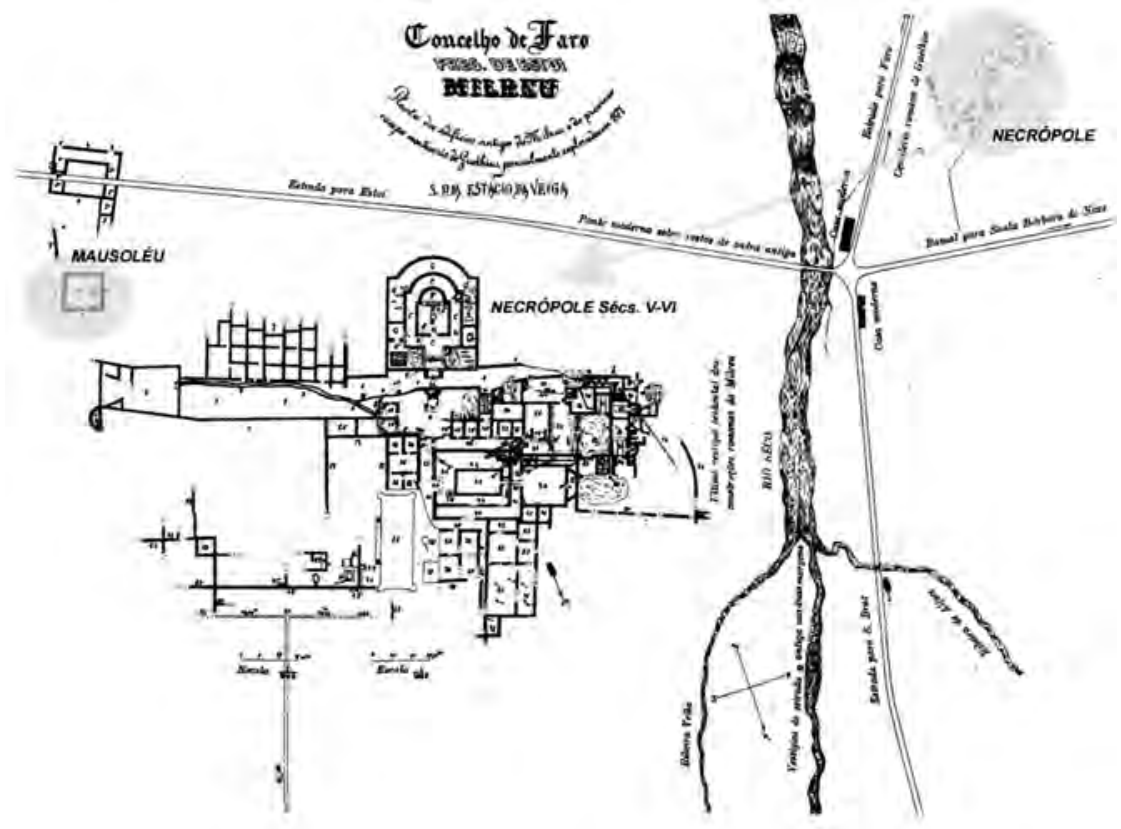

Figura 1 - Planta de Milreu elaborada por Estácio da Veiga, com a necrópole e um dos mausoléus da época imperial e a nova localização da necrópole da Antiguidade Tardia.

\footnotetext{
${ }^{19}$ Garcia Entero 2005-2006: 64.

${ }^{20}$ Wolfram 2011: 204-205.

${ }^{21}$ Gomes e Serra 1996; Bernardes 2008.

${ }^{22}$ Teichner 2008: 384 e 399.

${ }^{23}$ Alarcão, Étienne e Mayet 1995; Bowes 2006: 84.
} 
As frequentes deposições funerárias da Antiguidade Tardia em espaços notáveis e destacados dentro do conjunto edificado das antigas residências aristocráticas, justificam-se, para além de qualquer outro simbolismo, pelo facto de esses mesmos edifícios constituírem as marcas identitárias do território e, como tal, os locais propícios a receberem memoriais. Neste caso estarão em primeira linha os grandes edifícios das villae, como os templos ou mausoléus. De acordo com Libânio, no famoso apelo ao imperador Teodósio, em 386, em defesa dos templos (Pro Templis, XX, 42), era nesses edifícios de culto e nos seus ornamentos que residia muito da alma dos campos, o prestígio cidadão. Uma lei de 399, dirigida a Macrobio, vicarius Hispaniarum, reforça esse carácter dignificante dos templos e dos seus spolia ao especificar que apesar de se proibirem os sacrifícios não se destruam os ornamentos dos templos ${ }^{24}$, prática que deveria então ser corrente ao ponto de merecer a atenção legislativa. O desmantelamento em larga escala das mais prestigiantes e significativas estruturas clássicas e respectivos ornamenta, era feito não apenas para reaproveitar materiais mas como forma de combater os falsos deuses e a idolatria. Apesar do combate à idolatria estar na primeira linha das preocupações dos teólogos, estes reconheciam a importância da preservação dos edifícios pagãos não apenas por constituírem marcadores territoriais e referências identitárias como pela sua utilidade enquanto edifícios ${ }^{25}$. Sendo uma prática que ocorre um pouco por todo o lado, os fenómenos de destruição e pilhagem não terão atingido na Hispânia as proporções de outras regiões do Império; de igual modo, a conversão e adaptação a templos cristãos, pelo menos no meio rural, fica por demonstrar ${ }^{26}$. O templo pagão presta-se mal a qualquer adaptação a igreja cristã, uma vez que, ao contrário desta, nunca foi concebido para receber os fiéis no seu interior. É tendo em conta a sua marca identitária e prestigiante, mas também sagrada, que encontramos sepulturas paleocristãs a ocuparem a área interna e adjacente dos templos, como acontece em Milreu (Faro) ou em S. Cucufate (Vidigueira), ou a situarem-se na imediata proximidade de mausoléus ou templetes funerários, como é o caso do mausoléu templiforme do Cerro da Vila (Vilamoura).

A villa de Milreu tinha, na sua parte nascente, dois mausoléus destinados a depositar os restos fúnebres dos proprietários e, no lado oposto, a cerca de 250 metros e já na outra margem da ribeira que ali passa, a necrópole comum (Fig. 2). A partir de finais do século IV ou inícios do v, verifica-se o enterramento na área do temenos do templo e na sua envolvência. Foram identificadas várias sepulturas constituindo caixas que reaproveitam materiais da villa romana e inclusive do

\footnotetext{
${ }^{24}$ Arce 2006: 119.
}

${ }^{25}$ Como se pode ver no livro xvi do Código de Teodósio (CTh.16.10.19) que preconizava o aproveitamento dos templos, localizados dentro ou fora das cidades, para uso público: Aedificia ipsa templorum, quae in civitatibus vel oppidis vel extra oppida sunt, ad usum publicum vindicentur

${ }^{26}$ Arce 2006. 


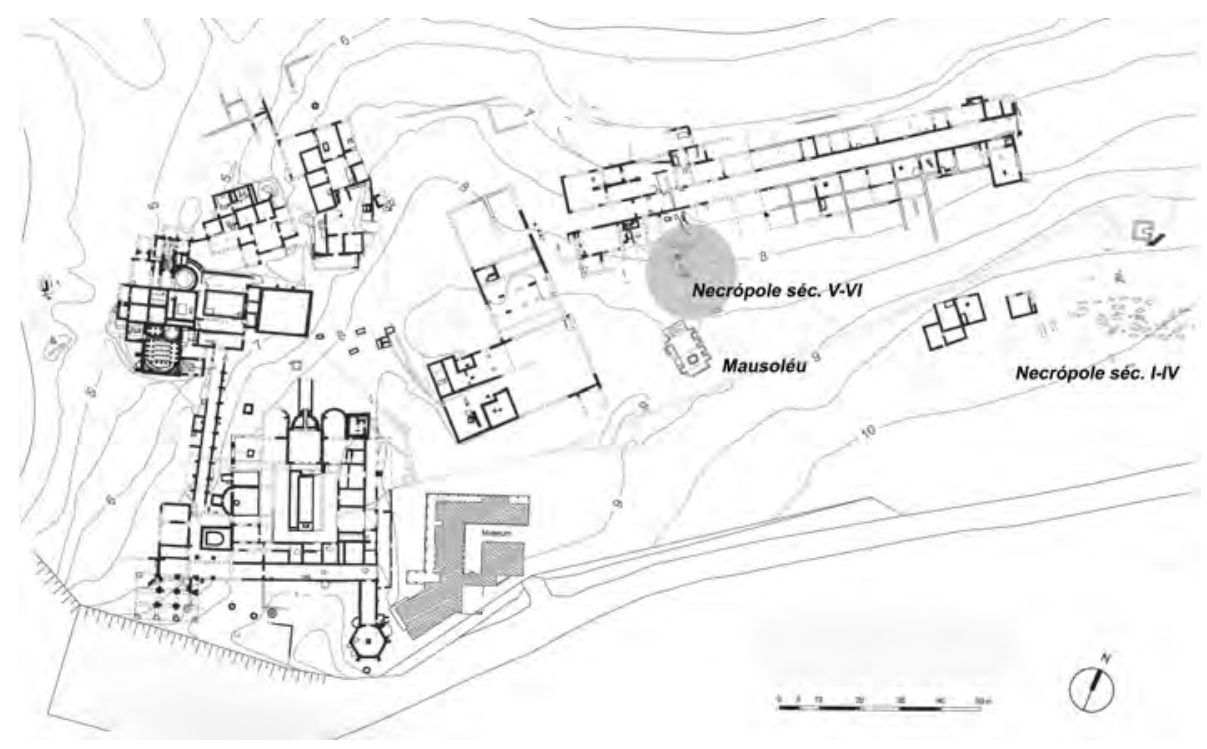

Figura 2 - Planta das ruínas do Cerro da Vila com os espaços funerários romano e da Antiguidade Tardia assinalados.

próprio templo, sendo algumas delas cobertas com opus signinum, à maneira de mensae. Como espólio possuíam as características bilhas e jarros frequentes neste tipo de contextos. Sobre uma destas sepulturas, na parte oeste do períbolo do templo, vai edificar-se um batistério no século vi, altura em que na parte oposta é erguido um pequeno edifício tendo no seu interior três sepulturas e interpretado como mausoléu ${ }^{27}$. Ainda que com funções sepulcrais, pelas características que apresenta pode também ser visto como um oratório ou capela funerária (Fig. 3); uma outra estrutura mais pequena e encostada pelo lado de fora ao recinto do templo, junto ao batistério, também tem sido classificada como mausoléu. Este e algumas das sepulturas datadas do século $\mathrm{v}$ ou vi possuem elementos reaproveitados do templo, nomeadamente mármores da cancela e da galeria da cella $a^{28}$, o que denota que já por esta altura o edifício de culto não estava activo e era objeto de ações de pilhagem. Tal fato reforça a ideia de que não teria continuado quer como templo pagão quer como igreja cristã.

\footnotetext{
${ }^{27}$ Hauschild 1980; Teichner 2006.

${ }^{28}$ Teichner 1994.
} 

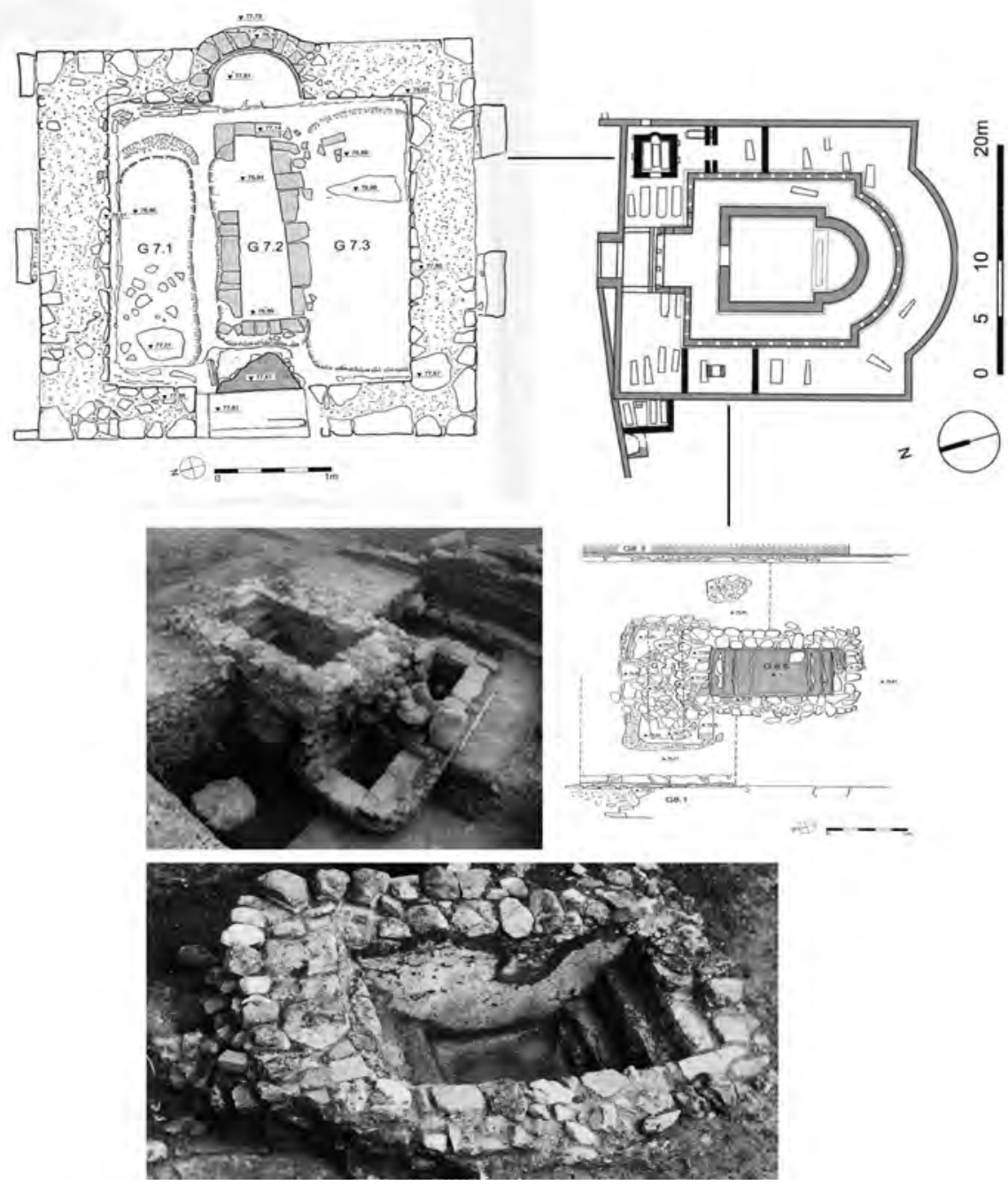

Figura 3 - Capela funerária/mausoléu e baptistério construídos no períbolo do templo de Milreu no século vi (Hauschild, 1980; Teichner, 2008, p. 264-265).

O melhor paralelo para Milreu de apropriação do temenos de um templo pagão como locus funebris é S. Cucufate. No edifício de culto e na sua periferia implantaram-se cerca de duas dezenas e meia de sepulturas em tudo semelhantes à da villa algarvia. Em ambos os templos, os enterramentos localizam-se preferentemente no períbolo notando-se a sua ausência na parte correspondente à cella, o que se justifica pelo facto desta parte do templo pagão ser o local reservado e exclusivo da divindade pagã, que, mesmo desacreditada nos seus poderes divinos, era temida (Fig. 4). 

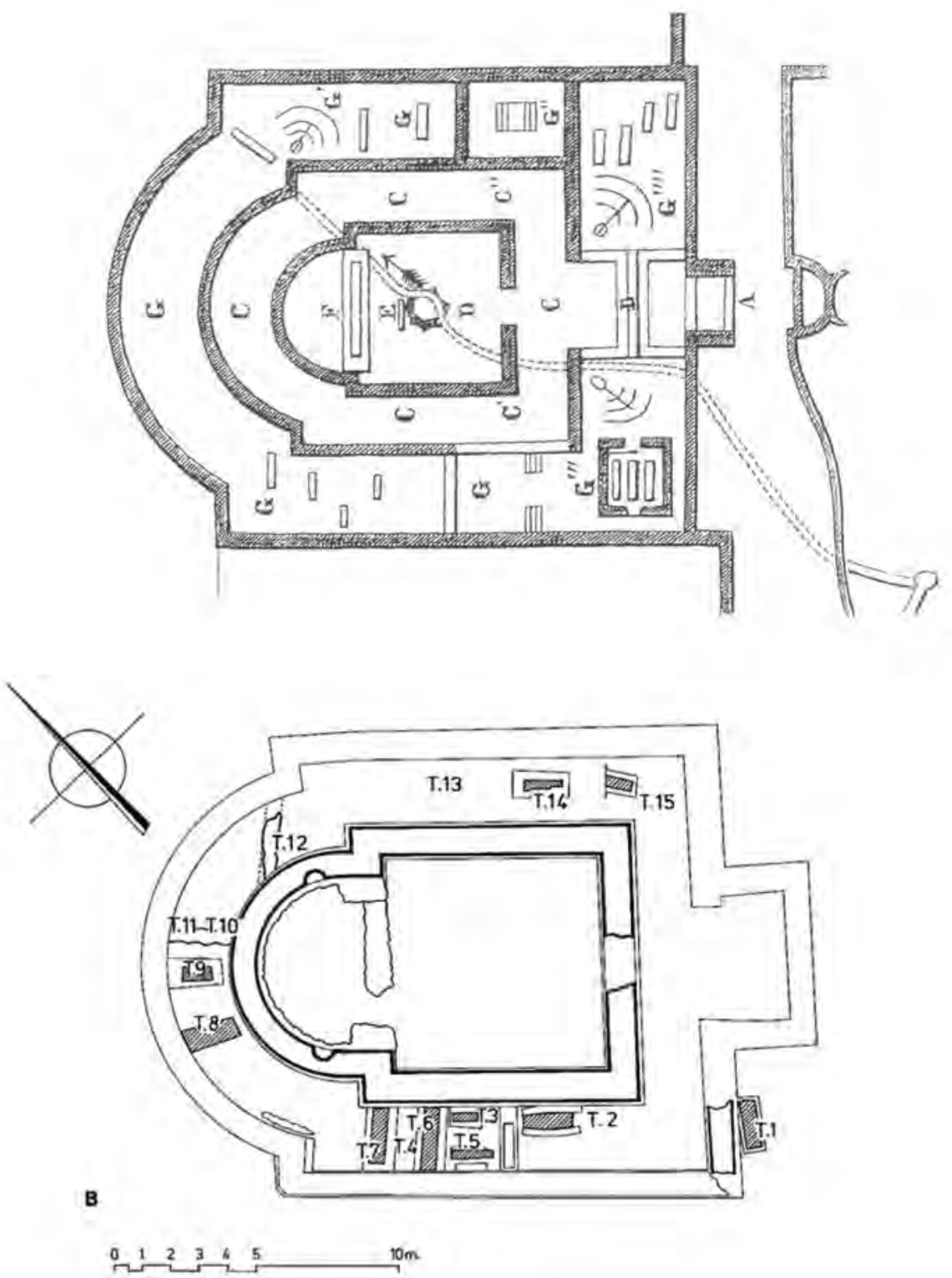

Figura 4 - Deposição funerária, a partir do século V, nos períbolos dos templos de Milreu (em cima e segundo planta de Britto Rebelo, apud Teichner, 2008:252) e de S. Cucufate (em baixo, segundo, Alarcão, Étienne e Mayet, 1990). 
A ocupação das áreas sagradas dos templos de Milreu e S. Cucufate tem levado recorrentemente a falar-se da cristianização destes templos pagãos, inferindo-se daí a sua conversão em igrejas cristãs. Se é certo que os dados arqueológicos nos permitem falar da apropriação por parte de comunidades cristãs do locus sacer do templo, nada dizem a respeito da cristianização ou conversão dos edifícios em igrejas cristãs. Ao contrário do que é proposto pelos autores das escavações, não existem dados inequívocos que o cemitério situado no edifício pagão de S. Cucufate é "prova da cristianização do templo talvez na primeira metade do século $\mathrm{V}$ d.C." 29 , ou que o denominado santuário de Milreu nos séculos v e vi "fue reutilizado como iglesia cristiana" ${ }^{30}$. A presença de sepulturas cristãs nos recintos de culto pagãos, não prova a conversão destes em igrejas mas demonstra apenas a apropriação por parte dos novos crentes de espaços sagrados, privilegiados e protegidos pelo seu estatuto de ligação ao divino. É a tradição sagrada da terra, o locus sacer, que se cristianiza, e não o edifício, o aedes templorum a que se refere uma lei imperial de $342^{31}$; este continua, todavia, a desempenhar um importante papel como marco territorial que assinala a presença das memórias dos defuntos que ali jazem.

Quer em Milreu quer em S. Cucufate, esse fenómeno de apropriação do espaço religioso pelas sepulturas cristãs centra-se nos séculos v e vi; no caso de S. Cucufate, a continuidade do culto cristão prosseguiu mas na parte da villa onde mais tarde se implanta o mosteiro homónimo. Uma estrutura identificada pelos arqueólogos no tablinum 4 da villa II, foi interpretada como uma igreja primitiva a que se terá seguido a instalação de um batistério ${ }^{32}$. Será esta a origem do culto cristão sob a égide de S. Cucufate, e não o templo pagão da villa. No caso de Milreu o culto, comprovado pela existência de um mausoléu ou capela funerária de características paleocristãs e de um batistério, não tem continuidade para além do século vi/vir.

Este poder de atração que nos campos o espaço sagrado pagão exerce sobre os primeiros enterramentos cristãos pode ser visto em outros templos rurais como no de Los Castillejos, uma villa suburbana a três quilómetros da cidade de Lacimurga (Badajoz), ou no de Carranque que, tal como nos exemplos portugueses, têm espaços funerários associados ${ }^{33}$. Também no Cerro da Vila temos uma primeira necrópole ocupada entre os séculos I e IV, afastada cerca de 150 metros da área residencial e tendo no meio um complexo fabril e um mausoléu

\footnotetext{
${ }^{29}$ Alarcão, Étienne e Mayet 1995: 385.

${ }^{30}$ Teichner 2006: 212.

${ }^{31}$ Quamquam omnis superstitio penitus eruenda sit, tamen volumus, ut aedes templorum, quae extra muros sunt positae, intactae incorruptaeque consistant (CTh. 16.10.3; apud Arce 2006: 116).

32 Alarcão Étienne e Mayet 1990: 267-268.

${ }_{33}$ Para o caso específico de Lacimurga ver Aguilar Saénz, Guichard e Lefebvre 1994:124-125; sobre os templos rurais em villae na Hispania veja-se Bowes 2006 e Bassani 2055, particularmente as páginas 93 a 99 para os casos da Lusitânia.
} 
templiforme (Fig. 1). A partir do século v o espaço fúnebre vai localizar-se junto àquele mausoléu ocupando parte do complexo industrial ${ }^{34}$. No caso do Cerro da Vila é o mausoléu templiforme pagão, enquanto espaço privilegiado, que vai atrair as sepulturas cristãs; algo semelhante poderá ter ocorrido em Torre de Palma, uma vez que a construção da Basílica em finais do séculos IV ou inícios do seguinte vai ocupar a área da necrópole pagã utilizada no Alto e Baixo Império (séculos I a IV), a 150 metros a norte da villa ${ }^{35}$.

Templos, templetes e mausoléus, ou seja, as estruturas que pelo seu prestígio e imponência constituíam autênticas marcas territoriais já imbuídas do espírito do sagrado, faziam o papel atribuído aos memoriais dos defuntos cristãos; este tipo de monumentos correspondem ao sentimento traduzido na expressão, splendida sepulcra ut posteri audiant, aplicada por João Crisóstomo por volta de 400 d.C ${ }^{36}$. Já Santo Agostinho no capítulo iv do seu tratado De Cura pro Mortuis Gerenda dizia:

Se é verdade que denominam de "Memorial" ou "Monumento" aos sepulcros vistosamente construidos, fazem-no, na verdade, para trazer à memória aqueles que, pela morte, foram subtraídos aos olhos dos vivos. Isto é feito para que as pessoas continuem a se lembrar deles, para que não aconteça de, tendo sido retirados da presença dos vivos, também sejam retirados do coração pelo esquecimento. Aliás, o termo "Memorial" indica claramente esse sentido de recordação, da mesma forma como "Monumento" significa "o que traz à mente", ou seja, o que a faz recordar ${ }^{37}$.

Em Quinta de Marim, onde se conhece um templo muito semelhante aos de Milreu e S. Cucufate ou mesmo aos de Los Castillejos e de Carranque, não se registam sepulturas. No sítio são conhecidos dois espaços funerários: o primeiro, misto com sepulturas e inscrições funerárias cristãs e pagãs, ocupa uma grande área construída, tendo sido recentemente sugerido que poderia tratar-se de uma basílica ${ }^{38}$; outro, a 200 metros para oeste do primeiro, reaproveita lápides e outros materiais romanos ${ }^{39}$. A avaliar pela planta de Estácio da Veiga que escavou a primeira necrópole, foi um edifício áulico que atraíu os enterramentos, à semelhança do que ocorre em Carranque onde o Palatium tardoromano é ocupado, já no

${ }^{34}$ Teichner 2008: 403-406.

${ }^{35}$ Wolfman 2011: 229, 255.

${ }^{36}$ Chavarria-Arnau 2007: 127.

${ }^{37}$ Sed non ob aliud vel Memoriae vel Monumenta dicuntur ea quae insignita funt sepulcra mortuorum, nisi quia eos qui viventium oculis morte subtracti sunt, ne oblivione etiam cordibus subtrahantur, in memoriam revocant, et admonendo faciunt cogitari: nam et Memoriae nomen id apertissime ostendit, et Monumentum eo quod moneat mentem, id est, admoneat, nuncupatur ( $\mathrm{St}^{\circ}$ Agostinho, De Cura pro Mortuis Gerenda, IV).

${ }^{38}$ Graen 2007.

${ }^{39}$ Rocha 1896; Santos 1972: 249-286. 
século vII, por um edifício de culto cristão e uma necrópole visigoda ${ }^{40}$. Nestes casos de necrópoles associadas a edifícios de culto cristão implantados sobre espaços de prestígio romanos, como é ainda o caso de Monte da Cegonha, seria interessante clarificar se as sepulturas são posteriores à instalação do edifício de culto ou se, ao contrário, este foi ali instituído porque o lugar estava já sacralizado por ter recebido anteriormente enterramentos cristãos.

Em Torre de Palma os dados apontam para que o leitmotiv da construção da basílica sobre a necrópole noroeste tenha, num primeiro momento, a ver mais com questões de sinalização e enquadramento funerário do que com uma função cultual, ainda que, a partir de certa altura, venha a ter um forte impacto evangelizador na região $0^{41}$.

No caso da necrópole paleocristã do Monte da Cegonha, localizada sob e nas imediações da Basílica que, a partir de finais do século Iv, ocupa a área das termas, todas as sepulturas, à excepção de um sarcófago em mármore, são construídas com materiais reaproveitados, tendo-se usado como tampas de alguns túmulos soleiras de portas e outras pedras arquitectónicas ${ }^{42}$. As tumbas foram reutilizadas várias vezes e como único espólio cada uma tinha a acompanhar um jarro trilobado em cerâmica comum. Teriam sido aqui depositadas até pouco depois das disposições regulamentares tomadas no II Concílio de Braga, em 572, altura em que os túmulos do interior da basílica são cobertos com um pavimento de opus signinum e se instala o batistério ${ }^{43}$. Também aqui a implantação da basílica poderá ter-se dado como forma de enquadrar sepulturas anteriores situadas na área das termas. A ideia que transparece destes casos, como já chamou a atenção Chavarria Arnau ${ }^{44}$, é que igrejas construídas em muitas villae, mais do que terem uma função evangelizadora das populações rurais, são ali implantadas para incorporar e comemorar estruturas funerárias tardo-antigas já existentes. Essa será, certamente, uma das razões porque boa parte dessas igrejas acabarão por ser abandonadas a partir do século viı, quando a organização do culto se começa cada vez mais a consolidar em torno das paróquias e outros centros religiosos.

${ }^{40}$ Fernández Ochoa et. al. 2011.

${ }^{41}$ Wolfram 2011: 255-257.

${ }^{42}$ Alfenim e Lopes 1995: 395.

${ }^{43}$ Idem: 398 . Do ponto de vista funerário há muitas similitudes com a realidade de Milreu onde soleiras de portas e outros materiais em tijolo e pétreos foram reutilizados em sepulturas, igualmente cobertas com um pavimento de opus signinum, e em que o batistério é implantado sobre um nível de enterramentos (Hauschild 1980; Teichner 1994).

${ }^{44}$ Spesso si può dimostrare come quello che in realtà costituì il seme degli edifici di culto in campagnanon furono le ville per sè bensì la presenza di areefunerarie. Le chiese costruite da privati (in generale a partire dal VI secolo) non sembrano nascere conl'intenzione precipua di evangelizzare le champagne (come ripete la storiografia relativa a questi temi) ma come monumenti per inglobare e comemorare strutture funerarie privilegiate tardoantiche (Chavarria Arnau 2007: 143). 
Face ao exposto, conclui-se que se no século $\mathrm{V}$ ainda se assiste a uma certa desorganização e proliferação dos espaços funerários, a partir do século vi e, sobretudo, no viI, essa proliferação tende a acabar, havendo um movimento de concentração em torno de lugares venerados, sejam basílicas, locais de tumulatio ad sanctos ou outros, contribuindo para a consolidação da imagem de cemitério cristão $0^{45}$. Esta consolidação do espaço funebris cristão é acompanhada de uma estruturação das sepulturas no sentido da sua definição como cistas ou caixas tumulares, onde recorrentemente se observa um caraterístico espólio de bilhas e jarros que perpetua um hábito claramente pagão. A presença do cantharus em sepulturas cristãs se, por um lado, continua essa longa tradição pagã de fazer acompanhar o morto, na sua viagem para o além, por objetos do quotidiano, tem, por outro, o significado simbólico, no quadro da nova fé, de purificação associada à água lustral. ${ }^{46}$ Este é apenas mais um sintoma da enorme confusão e ambiguidade de ritos que reinava nos primeiros tempos do cristianismo, de resto refletida pela legislação eclesiástica, e que demonstra uma certa continuidade nos hábitos de enterrar ${ }^{47}$. Esta transição na continuidade, corporiza diversas ambiguidades e confusões entre práticas pagãs e cristãs particularmente angustiantes na hora de escolher o lugar da sepultura, cuja definição não foi objeto de preocupação por parte dos bispos da Igreja antes do século viı. Coube, pois, aos primeiros cristãos descobrirem o locus funebris mais adequado ao enterramento, como se depreende pelo pedido de conselho que Paulino, bispo de Nola na Campânia, faz a Santo Agostinho (vide supra). Os locais mais prestigiantes e dignificantes do meio rural, os mais marcantes do território e que definem pela sua monumentalidade a identidade dos campos, como os templos, serão locais privilegiados para a deposição dos túmulos e (co)memoração dos mortos, até porque, como locais de culto, são lugares sagrados onde o espírito celeste habitou por algum tempo ${ }^{48}$. Estes loci sacer que são a almas dos campos, no dizer de Libânio, acabarão por servir de loci funebris durante os séculos $\mathrm{V}$ a VI, até que são abandonados quando, a partir do século VII, se começam a definir e regulamentar os rituais e locais de enterramento cristão. Mas esta apropriação das áreas sagradas dos templos para enterrar não significa que esses templos, como os de Milreu, de S. Cucufate ou de Los Castillejos, tenham sido cristianizados e convertidos em igrejas. Em qualquer destes casos, os dados arqueológicos mostram-nos apenas uma ocupação sepulcral cristã

\footnotetext{
${ }^{45}$ Cordoba, no que diz respeito às áreas urbanas, ilustra bem o que acabou de se dizer. A este propósito ver Sanchéz Ramos 2007 e 2010.

${ }^{46}$ Maciel 1996: 166.

${ }^{47}$ André Carneiro (2009), que tratou este problema, apresenta vários exemplos desta continuidade.

${ }^{48}$ A expressão é de Lactâncio, Divina Institutiones, II, 12 (apud, Maciel, 1996: 166).
} 
A transformação do espaço funerário no ocidente entre os séculos IV e vi. Ambiguidades e loci sepulturae em espaços rurais do sul da Lusitânia: o caso dos templos

do lugar e não a conversão dos aedificia ipsa templorum, edifícios esses que agora mais não são do que marcadores de memórias.

Se as novas e variadas realidades com a topografia e com o espaço de deposição funerária, quer em meio urbano quer em meio rural, sinalizam concepções religiosas do além em transição, são também indícios da mutação de poderes e ainda de uma certa indefinição e desregulamentação da ars moriendi, típicas de um período de grande conflitualidade religiosa e mental, onde o instituído já perdera boa parte do sentido e o que chegava de novo ainda não sedimentara. 


\section{Bibliografia}

AGUILAR SÁENZ, A.; GUICHARD, P.; LEFEBVRE, S. (1994) La ciudad antigua de Lacimurga y su entorno rural. In: Gorges (ed.) Actas de la mesa redonda internacional El medio rural en Lusitania romana - Formas de hábitat y ocupación del suelo. Salamanca, p. 109-130.

ALARCÃO, J.; ÉTIENNE, R.; MAYET, F. (1990) Les villas romaines de São Cucufate (Portugal). Paris.

(1995) Os monumentos cristãos da villa de S. Cucufate. IV Reunió de Arqueología (Paleo) Cristiana Hispànica. Barcelona (Monografias de la secció històrico-arqueològica 4), p. 383-387.

ALBA CALZADO M. (2004) Evolución y final de los espacios romanos emeritenses a la luz de los datos arqueológicos (pautas de transformación de la ciudad tardoantigua y altomedieval). In: Nogales Basarrate (ed.) Augusta Emerita. Territorios, espacios, imágenes y gentes en Lusitania romana. Merida (Monografias Emeritenses, 8), p. 207-255.

ALFENIM, R. e LOPES M.C. (1995) A basílica Paleo-Cristã/Visigótica do Monte da Cegonha (Vidigueira). In: IV Reunió de Arqueología (Paleo)Cristiana Hispànica. Barcelona (Monografias de la secció històrico-arqueològica 4), p. 389-398.

ARCE J. (2006) Fana, templa, delubra destrui praecipimus: el final de los templos de la Hispania romana. Archivo Español de Arqueología 79, p. 115-124.

ARIÈS, P. (1988) O Homem Perante a Morte, vol. I, Mem Martins.

BASSANI, M. (2005) Ambienti e edifici di culto domestici nella Peninsola ibérica. Pyrenae 36:1, p. 71-116.

BERNARDES, J. P. (2008) Intervenção Arqueológica de Emergência no Sítio Romano de Loulé-Velho (Quarteira). Al-'ulyà - revista do Arquivo Municipal de Loulé 12, p. 9-22.

BOWES K. (2006) Building Sacred Landscapes: Villas And Cult. In: Chavarria; Arce Brogiolo (eds.) Villas Tardoantiguas en el Mediterráneo Occidental. Anejos de AEspA. 39, p. 73- 95.

CARNEIRO, A. (2009) Sobre a Cristianização da Lusitânia: novas reflexões a partir dos dados históricos e das evidências arqueológicas. Espacio, Tiempo y Forma. Serie I, t. 2, p. 205-220.

CHAVARRÍA ARNAU, A. (2007) Splendida sepulcra ut posteri audiant. Aristocrazie, mausolei e chiese funerarie nelle campagne tardoantiche. In: Brogiolo; Chavarria Arnau (Ed.), Archeologia e società tra Tardo Antico e Alto Medioevo. Mantova (Documenti di Archeologia 44), p. 127-146. 

Ambiguidades e loci sepulturae em espaços rurais do sul da Lusitânia: o caso dos templos

CUNHA, M. (2008) As necrópoles de Silveirona (Santo Estêruão, Estremoz). Do mundo funerário romano à Antiguidade Tardia. Lisboa, (O Arqueólogo Português Supl. 4).

FERNÁNDEZ OCHOA, C.; BENDALA GALÁN, M.; GARCÍA-ENTERO, V.; VIDAL ÁLVAREZ, S. (2011) Cubierta de sarcófago con el ciclo de Jonás hallada en Carranque (Toledo). Archivo Español de Arqueología 84, p. 231-242.

GARCÍA ENTERO, V. (2005-2006) Las transformaciones de los balnea rurales domésticos durante la Antigüedad Tardía en Hispania (ss. IV-VI). Cuadernos de Prehistoria y Arqueología. 31-32, p. 61-82.

GRAEN, D. (2007) O sítio da Quinta de Marim (Olhão) na época tardo-romana e o problema da localização da Statio Sacra. Revista Portuguesa de Arqueologia. 10:1, p. 275-288.

GOMES, M. V. e SERRA, M. P. (1996) Loulé-Velho (Quarteira, Loulé). Resultado da primeira campanha de escavações arqueológicas. Al-Ulyã Revista do Arquivo Histórico Municipal de Loulé 5, p. 29-49.

HAUSCHILD, T. (1980) Milreu-Estoi (Algarve): Untersuchungen neben der Taufpiscina und Sondagen in der Villa. Kampagnen 1971 und 1979. Madrider Mitteilungen 21, p. 189-219.

LANCHA, J. e ANDRÉ, P. (2000) La villa de Torre de Palma, Corpus des mosaïques romaines du Portugal, II, Conventus Pacensis. Lisboa.

LOPEZ MELERO, R. (1997) Enterrar en Urso. Studia Historica, Historia Antigua. 15 (La Lex Ursonensis), p. 105-118.

MACIAS, S. (2005) Mértola, o último porto do Mediterrâneo. Mértola. 3 Vols.

MACIEL, M.J.(1996) Antiguidade Tardia e Paleocristianismo em Portugal. Lisboa.

MALONEY S. J.; HALE, J. R. (1996) - The Villa of Torre de Palma (Alto Alentejo). Journal of Roman Archaeology 9 p. 275-294.

NOGALES BASARRATE, T.; MÁRQUEZ PÉREZ, J. (2002) - Espacios y tipos funerários en Augusta Emerita. In: Vaquerizo (Ed.) Espacios y usos funerários en el Occidente Romano. Córdoba, p. 113-144.

ROCHA, A. dos S. (1896) - Notícia de Algumas Estações Romanas e Árabes do Algarve. O Archeologo Português, Lisboa II: 8, p. 77-79.

RÉBILLARD, É. (1999) - Église et sépulture dans l'Antiquité tardive (Occident latin,IIIe-VIesiècles).Annales. Histoire, Sciences Sociales.54N.5,p.1027-1046.

(2003) - Religion et sépulture. L'Eglise, les vivants et les morts dans l'Antiquité Tardive. Paris. (ed. inglesa de 2009: The Care of the Dead in Late Antiquity. Ithaca). 
SÁCHEZ RAMOS, I. (2007) - La cristianización de las necrópolis de Cordvba. Fuentes escritas y testimonios arqueológicos. Archivo Español de Arqueología 80, p. 191-206.

(2010) Corduba durante la Antigüedad tardía. Las necrópolis urbanas. Oxford (BAR IS 2126).

SANTOS, M.L.E.V.A (1972) - Arqueologia Romana do Algarve. Lisboa, Vol. II.

TEICHNER, F. (1994) Acerca da vila romana de Milreu/Estoi: continuidade da ocupação na época árabe. Arqueologia Medieval 3, p. 89-100.

(2006) - De lo romano a lo árabe. La transición del sur de la provincia de Lusitania a al-Gharb al-Andalus: nuevas investigaciones en los yacimientos de Milreu y Cerro da Vila. Anejos de AEspA, XXXVIII, p. 207-220.

(2008) - Zwischen Land und Meer - Entre tierra y mar. Studien zur Architektur und Wirt-schaftsweise ländlicher Siedlungen im Süden der römischen Provinz Lusitanien. Merida (Stvdia Lvsitana3) 2. vols.

TEICHNER, et. al. (2007) - Sebastião Philippes Martins Estácio da Veiga e as Necrópoles Romanas de Ossonoba (Faro). Xelb 7 (Actas do IV Encontro de Arqueologia do Algarve), p. 159-178.

VAQUERIZO, D. (coord.) (2001) - Funus Cordubensium - Costumbres Funerarias en la Cordoba Romana Córdoba.

VIVES, J. (1963) - Concílios Visigóticos e hispano-romanos, Barcelona.

WOLFRAM, M. (2011) - A Cristianização do Mundo Rural no Sul da Lusitânia, Lisboa (Tese de doutoramento apresentada à Universidade de Lisboa). 